\title{
The Influence of Inorganic Salts on the Phase Diagram and Separating Ability of Aqueous Biphasic System: Peg/Sodium Citrate-Water
}

\author{
Shahbazova M. Gunel, Masimov A. Eldar \\ Department of Physics, Baku State University, Baku, Azerbaijan \\ Email: shahbazova.gunel@mail.ru
}

How to cite this paper: Gunel, S.M. and Eldar, M.A. (2021) The Influence of Inorganic Salts on the Phase Diagram and Separating Ability of Aqueous Biphasic System: Peg/Sodium Citrate-Water. Open Access Library Journal, 8: e8105.

https://doi.org/10.4236/oalib.1108105

Received: October 20, 2021

Accepted: December 3, 2021

Published: December 6, 2021

Copyright $\odot 2021$ by author(s) and Open Access Library Inc.

This work is licensed under the Creative Commons Attribution International License (CC BY 4.0).

http://creativecommons.org/licenses/by/4.0/

\begin{abstract}
The purpose of the proposed research is to ensure that the value of the distinction is adjusted to each application by using various supplements to separate and clean up biological objects. The work presents the results of studies of the phase diagram of the biphasic system composed of polyethylene glycol (PEG)/sodium citrate-water and the effect of inorganic salts (sodium sulfate, sodium carbonate, sodium nitrate, potassium sulfate, potassium chloride, potassium iodide, potassium bromide) on the separating ability of this biphasic system. Analysis of the data presented shows that the change in the parameters of the phase diagram and different values of the separating ability (for PEG-sodium citrate-water system $n^{*}=9.3$ ) of the biphasic system, depends on the nature of the additives. The utilized inorganic salts change the structure of water clusters. Following the change, the biphasic system component relative hydrophobicity rises, which results in phase separation. The displacements of the binodal of the phase diagram in the direction of the origin of coordinates, an increase in the area of the heterogeneous region of the diagram upon the introduction of the studied salts indicate that these salts have a structuring effect on the aqueous medium.
\end{abstract}

\section{Subject Areas}

Biophysics, Physical Chemistry

\section{Keywords}

PEG, Sodium Citrate, Biphasic Systems, Separating Ability, Inorganic Salts 


\section{Introduction}

Aqueous biphasic systems were formed when two particular chemically different polymers (e.g., dextran (dex) and polyethylene glycol (PEG)) were mixed at appropriate concentrations in an aqueous solution, and the solution was separated into two immiscible phases. One phase is rich in one polymer, and the second phase is rich in the other polymer, as with water as a solvent in both phases [1] [2] [3].

It should be noted that such incompatibility of components in a common solvent (in water) could also be observed in the mixtures of one polymer with some inorganic and organic salts [4] [5].

Albertson et al.'s systematic studies of various water-polymer two-phase systems led to the emergence of a new universal, highly effective, gentle, cost-effective method of separation and purification of a wide variety of biological materials [6].

Because the solvent in both phases of the studied systems is water $(70 \%$ $80 \%$ ), proteins, nucleic acids, viruses, cells, etc., can be introduced into such systems. Depending on their characteristics and distribution conditions (nature and concentration of phase-forming components, nature and concentration of additives, etc.), these biological objects are unevenly distributed over coexisting phases without losing their intact properties.

It should be noticed that the method (method of separation) is also successfully used for the quantitative assessment of the relative hydrophobicity of high molecular weight compounds, which could not be determined previously [7].

The aqueous two-phase system (ATPS) composed of PEG 6000 and sodium citrate (SC) has been proposed to recover the valuable soluble proteins from tannery wastewater. Thus, the proposed ATPS can serve as an alternative to the conventional precipitation method to recover the soluble proteins from tannery wastewater [8].

Aqueous biphasic systems were used during downstream processing, mainly in biotechnological and chemical industries [9]. Aqueous biphasic extraction processes offer the potential for low-cost, highly selective separations. This counter-current extraction technique is involved in the selective partitioning of either dissolved solutes between two immiscible aqueous phases [10].

Aqueous biphasic systems have been successfully used to detect veterinary drug residues in food, separation of precious metals, sewage treatment, and a variety of other purposes [11].

The practical application of aqueous two-phase systems (ATPS) to extraction processes has been exploited for several years to recover biological products [12]. A critical overview of the fundamental thermodynamic properties related to forming aqueous two-phase systems and their application to extraction and purification of bioparticles was studied previously [12].

For describing aqueous biphasic systems, it is traditional to study the phase diagram of the system (binodal curves, connecting lines, separating ability, etc.). The properties of the aqueous medium of the phases of a two-phase system and 
the nature of the phase diagrams are affected by different factors like concentration of phase-forming polymers, concentration and composition of salts [9] [13], their molecular weight, nature of the second phase-forming component and solvent, temperature, the presence of low molecular weight additives [13]-[18].

Studying the effect of various additives, in particular, inorganic salts, on the water-polymer biphasic system is important since additives of inorganic salts are widely used to regulate the distribution of biological materials in these systems [19]. Similar research was carried out for biphasic systems, e.g., dextran-PEG, dextran-PVP, and dextran-ficoll [20] [21]. The works presented that the degree of influence of the addition of inorganic salts on the conditions of phase separation in the biphasic systems under consideration is associated with the position of the salt in the lyotropic series of the ability of salts to precipitate proteins in aqueous solutions [22]. However, it seems interesting to study the effect of inorganic salts (sodium sulfate, sodium carbonate, sodium nitrate, potassium sulfate, potassium chloride, potassium iodide, and potassium bromide) on the separation of biphasic systems into polymer-organic and salt-water phases.

In the presented work, the phase diagrams of the water-polymer biphasic system PEG 6000-sodium citrate $\left(\mathrm{C}_{6} \mathrm{H}_{5} \mathrm{O}_{7} \mathrm{Na}_{3}\right)$-water and the concentration effect of the sodium nitrate on the position of the binodal, on the value of the separating ability of the system were investigated. The PEGs with different molecular weights are widely used polymers in aqueous two-phase systems (ATPS) due to their low toxicity, low price, and low volatile nature [13].

\section{Results and Discussions}

The aqueous two-phase systems (water + polymer + salt) based on PEG 6000 and sodium citrate were prepared using the phase diagram. The weighed dry polymer is added to a given quantity of double distilled water and waited until completely dissolved. The obtained solutions are boiled for sterilization and filtered. Given the presence of adsorbed water in the primary polymers, the concentrations of the solutions are determined (calculated) after they have dried mycophiles. Concentrations of the prepared solutions ranged from $38 \div 40 \%$. To obtain two-phase systems a predetermined quantity of sodium citrate was dissolved in water. Afterwards, in order to form the ATPS, the corresponding quantity of PEG according to the composition was added to the sodium citrate solution. Finally, the biomass was added. The system is then intensively mixed, placed in a thermostat, and phased until it reaches equilibrium (approximately 24 hours). In some cases, the system rotates rapidly through a centrifuge to achieve equilibrium in a short time (20 - 40 minutes at 4400$)$.

For illustrating aqueous biphasic polymer systems, it is conventional [1] to investigate the phase diagram-binodal curves, where the weight vs concentrations of the phase-forming components, the tie line, its length and angle of inclination, separation capacity, etc., are plotted along the coordinate axes. Figure 1 shows the binodal curve of the PEG (6000)-sodium citrate/water tie line, which 


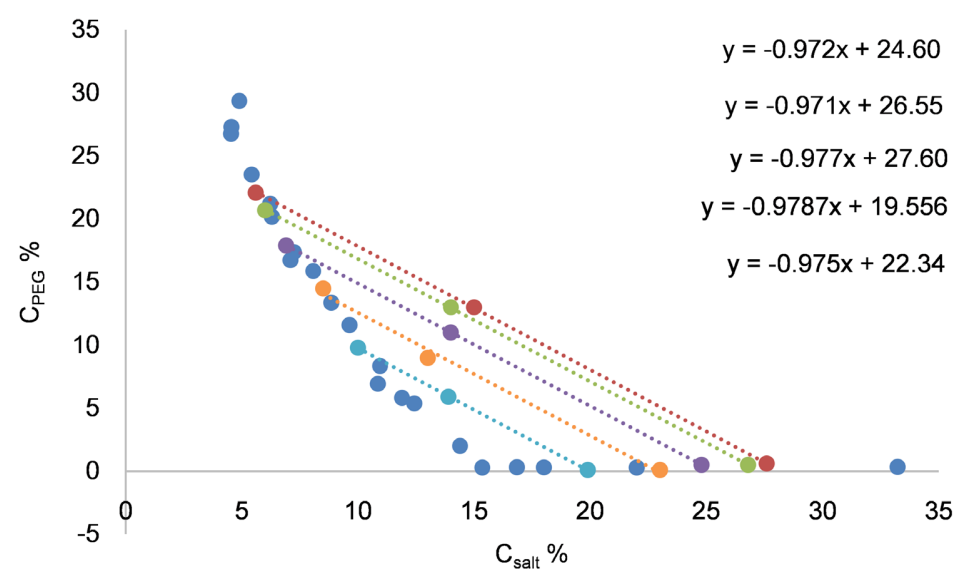

Figure 1. Binodal curve and tie lines of the biphasic system PEG/sodium citrate $-\mathrm{H}_{2} \mathrm{O}$.

is defined based on the method of least squares equation.

The binodal curve and tendency angle of connecting (or tie) lines are taken as the main characteristic of polymer-polymer-water two-phase systems. The phase diagrams depend on many factors: the nature of polymers, their molecular weights, temperature, the presence of low molecular weight additives, etc. [20].

Figure 2, Figure 3, and Table 1 show the experimental results describing the binodal and tie lines of the phase diagram of the studied biphasic system in the absence and presence of various salts, where the concentrations of the phase-forming components are plotted along the coordinate axes. The curves (binodal) delimit the region of existence of homogeneous solutions (under the binodal) and the region of existence of heterogeneous (above the binodal) solutions.

Figure 3 describes a change in the position of binodal in the presence of $\mathrm{Na}$ $\mathrm{NO}_{3}$ at different concentrations.

As it follows from the results obtained by adding all salts to the system, the binodal are somewhat displaced towards the origin of coordinates extensively when the salt concentration increases (Figure 3). Proportionally the area of the heterogeneous region of the phase diagram increases. The variations in the system with two phases occur at lower concentrations of the phase-forming components, which indicates that the structuring of the aqueous medium of the system takes place under the influence of added salts. The structuring of the aqueous medium of the biphasic system phases is due to changes in the degree of hydration of the phase-forming components. Therefore, the differences in the relative hydrophobic properties of the phases increase, leading to worse compatibility of these components in the common solvent, and naturally, to separating the system into two phases at lower concentrations the phase-forming components.

Figure 4 shows the data describing the concentration effect of sodium nitrate on the total concentration of phase-forming components at the critical point of the studied biphasic system (PEG and sodium citrate). 


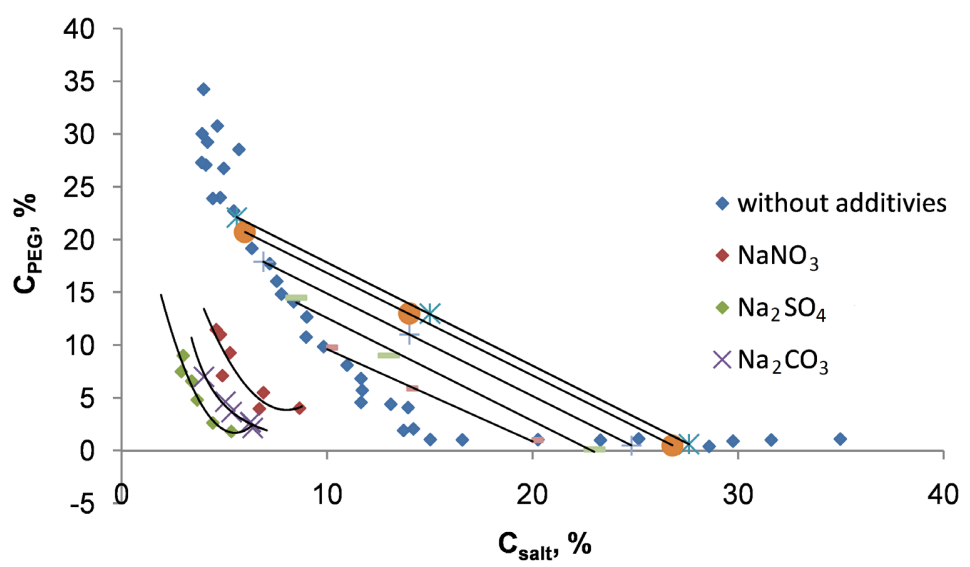

Figure 2. The influence of salts $\left(\mathrm{NaNO}_{3}, \mathrm{Na}_{2} \mathrm{CO}_{3}, \mathrm{Na}_{2} \mathrm{SO}_{4}\right)$ on the formation of biphasic systems PEG- $\mathrm{C}_{6} \mathrm{H}_{5} \mathrm{O}_{7} \mathrm{Na}_{3}-\mathrm{H}_{2} \mathrm{O}$.

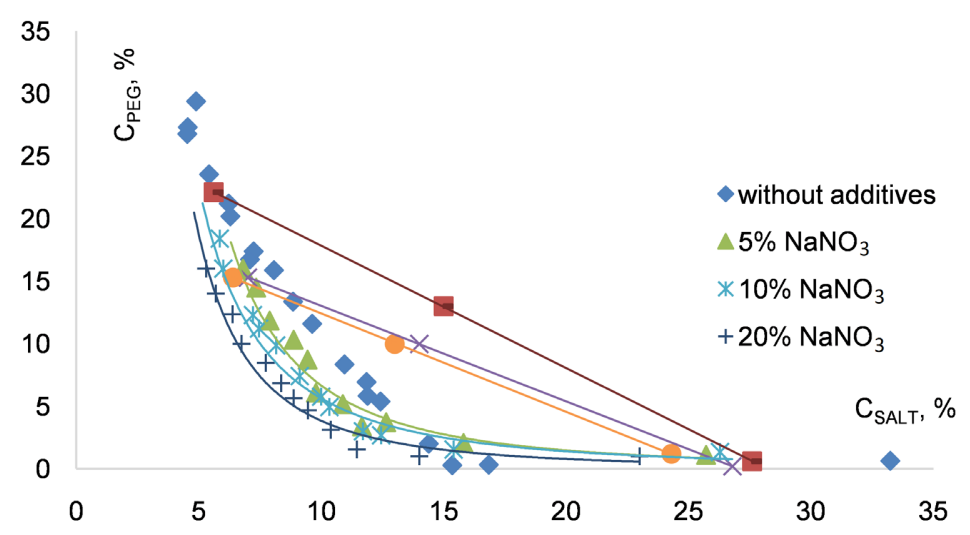

Figure 3. The influence of $\mathrm{NaNO}_{3}$ on the phase diagram of aqueous biphasic systems PEG-sodium citrate.

Table 1. Changes of the critical point of the binodal of the PEG (6000) - $\mathrm{C}_{6} \mathrm{H}_{5} \mathrm{O}_{7} \mathrm{Na}_{3}-\mathrm{H}_{2} \mathrm{O}$ system with varying $\mathrm{NaNO}_{3}$ concentrations.

\begin{tabular}{cccccc}
\hline $\begin{array}{c}\mathrm{NaNO}_{3} \text { con. } \\
(\mathrm{w} \%)\end{array}$ & $\mathrm{C}_{\mathrm{cr}}$ PEG \% & $\mathrm{C}_{\mathrm{cr}}$ salt \% & $\begin{array}{c}\Sigma \mathrm{C}_{\mathrm{cr}} \\
\%\end{array}$ & $\begin{array}{c}\sigma, \mathrm{mN} / \mathrm{m} \\
\left(\mathrm{NaNO}_{3}+\right. \\
\left.\mathrm{H}_{2} \mathrm{O}\right)\end{array}$ & $\Delta \sigma, \mathrm{mN} / \mathrm{m}$ \\
\hline 5 & 1.73 & 12.65 & 14.38 & 72.1 & 0.9 \\
10 & 1.68 & 12.45 & 14.13 & 72.8 & 1.6 \\
15 & 1.60 & 11.9 & 13.63 & 73.8 & 2.6 \\
20 & 1.53 & 11.45 & 12.98 & 74.4 & 3.2 \\
\hline
\end{tabular}

As shown in Figure 4, with an increase in the concentration of the added salt $\left(\mathrm{NaNO}_{3}\right)$, the total concentration of phase-forming components decreases at the critical point for separating the system into two phases.

Figure 5 shows changes in the surface tension of water $(\Delta \sigma)$ depending on the concentration of salt $\left(\mathrm{NaNO}_{3}\right)$ and based on the data in Figure 4 and Figure 5. The dependence of the shift of the value of the total concentration $\Sigma C_{i}^{c r}$ of the 


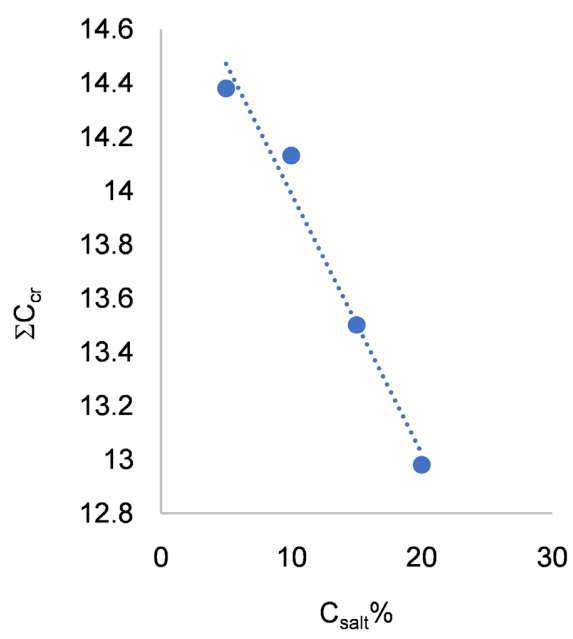

Figure 4. Dependence of total concentration of phase-forming components from the concentration of sodium nitrate

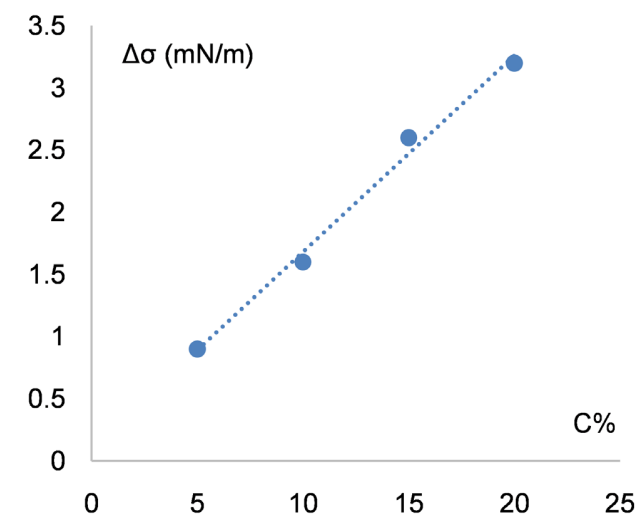

Figure 5. Changes in the surface tension of water $(\Delta \sigma)$ depending on the concentration of $\mathrm{NaNO}_{3}$

phase-forming components of the biphasic system on the surface tension (Figure $6)$.

Figure 6 describes the magnitude of the shift in the total concentration of the system components under the influence of the added salt $\left(\mathrm{NaNO}_{3}\right)$ and its effect on the surface tension of pure water. There is a good correlation indicating the structuring of water under the influence of the introduced salt into the system.

For a more detailed analysis of the results obtained, let us consider the mechanism of the effect of salts on water based on Samoilov's theory [23].

According to this theory, an ion (cation or anion) destroying the structure of water means an ion, in the vicinity of which water molecules exchange with molecules of "free" water in the volume with a higher frequency than molecules of "free" water among themselves, i.e.

$$
v_{\left(\mathrm{H}_{2} \mathrm{O}^{0}-\mathrm{H}_{2} \mathrm{O}^{h}\right)}<V_{\left(\mathrm{H}_{2} \mathrm{O}^{0}-\mathrm{H}_{2} \mathrm{O}^{0}\right)}
$$

where $\mathrm{H}_{2} \mathrm{O}^{0}$-water in volume, $\mathrm{H}_{2} \mathrm{O}^{h}$-water in the hydration shell of the ion. In other words, the settled life of a water molecule near a water ion in the 


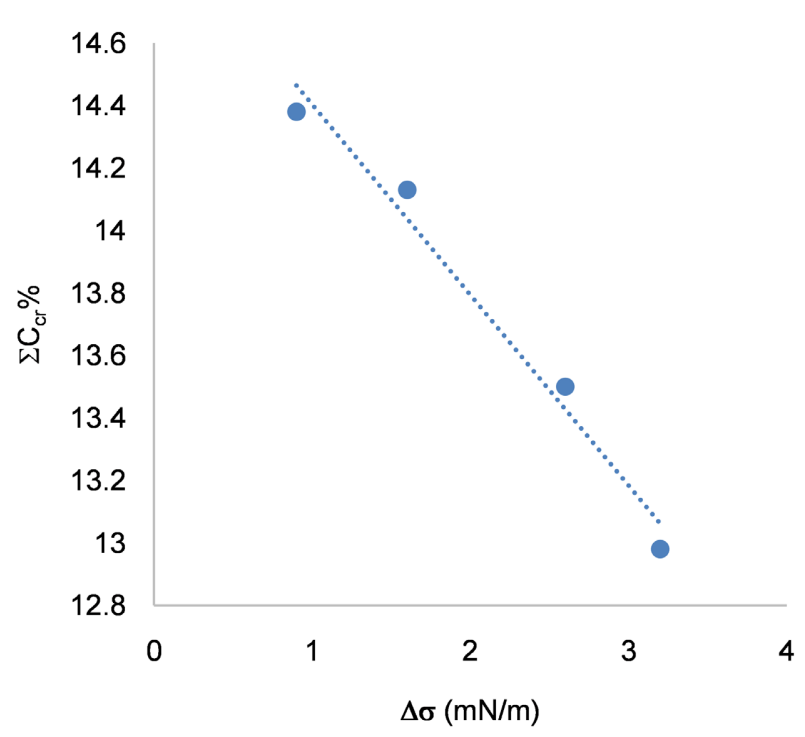

Figure 6. Dependence of total concentration of the phase-forming components $\Sigma C_{i}^{c r}$ from $\Delta \sigma$.

volume

$$
\tau_{\mathrm{H}_{2} \mathrm{O}^{h}}<\tau_{\mathrm{H}_{2} \mathrm{O}^{0}}
$$

And an ion that stabilizes the structure of water means ions for which the following conditions are met:

$$
v_{\mathrm{H}_{2} \mathrm{O}^{0}}-v_{\mathrm{H}_{2} \mathrm{O}^{h}}<v_{\mathrm{H}_{2} \mathrm{O}^{0}}-v_{\mathrm{H}_{2} \mathrm{O}^{0}}
$$

and

$$
\tau_{\mathrm{H}_{2} \mathrm{O}^{h}}>\tau_{\mathrm{H}_{2} \mathrm{O}^{0}}
$$

Our results indicate that in our case, conditions (3) and (4) hold. When salts are introduced into the system, water molecules of anions (all studied salts have the same cations) exchange with "free water" molecules at a lower frequency than free water molecules with each other, which ultimately leads to the structuring of all water molecules.

All the above discussion makes it possible to qualitatively explain the results obtained in this work on the effect of salt additions on the characteristics of the phase diagram of the PEG/sodium citrate-water.

Thus, the displacement of the binodal of the phase diagram towards the origin of coordinates, an increase in the area of the heterogeneous region of the diagram upon the introduction of the studied salts $\left(\mathrm{NaNO}_{3}, \mathrm{Na}_{2} \mathrm{SO}_{4}, \mathrm{Na}_{2} \mathrm{CO}_{3}, \mathrm{KCl}\right.$, $\mathrm{KBr}, \mathrm{KJ}, \mathrm{K}_{2} \mathrm{SO}_{4}$ ), as well as a decrease in the total concentration of phase-forming components at the critical point of the two-phase system with an increase in salt concentration (for example, $\mathrm{NaNO}_{3}$ ) clearly indicates that these salts have a structuring effect on the aquatic environment of the system.

It should be emphasized that changes in the characteristics of an aqueous bi- 
phasic system naturally affect the distribution of various substances in these biphasic systems. To quantitatively characterize the difference in the affinity of the phases to the distributing substance, we studied the separating ability $\left(\mathrm{n}^{*}\right)$ of the biphasic PEG (6000) -sodium citrate-water system at $\mathrm{T}=298.15 \mathrm{~K}$ in the absence and presence of various additives. The obtained data are presented in $\mathrm{Ta}$ ble 2 . The separating ability of the system is determined by the method proposed in work [6].

The results obtained show that the addition of urea to the aqueous biphasic system reduces its separation capacity $\left(\mathrm{n}^{\star}=5.20\right.$ in the presence of $1.25 \mathrm{~mol} / \mathrm{l}$ of urea, while $n^{*}=6.5$ in the absence of additives). In contrast, the addition of carbohydrates, such as glucose and sucrose to the system leads to an increase in the separation capacity of the system.

Urea changes the value $\left(\mathrm{n}^{*}\right)$ associated with the destruction of the water structure in the corresponding phases. Urea also leads to an increase in PEG hydration and a change in the latter molecule nearest the aqueous environment, which boosts the compatibility of the system components. This contributes to the convergence of the properties of the phases, consequently, a more uniform distribution of substances between the two phases, and leads to a decrease in the separation capacity.

With the addition of carbohydrates, the structuring of the aqueous environment takes place, which should lead to a decrease in PEG hydration. Eventually, it leads to a deterioration of hydrophobic phases. The distribution coefficient can be elevated via using mineral salts results in an increase in the separation capacity of the system.

A significant increase in the separating ability of the investigated biphasic system with the introduction of salts (Table 2) indicates that these salts very strongly stabilize the structures of the aqueous medium in the phases of the aqueous biphasic system.

Table 2. Separating ability PEG_-sodium citrate-water in the presence of some salts.

\begin{tabular}{|c|c|}
\hline SYSTEMS & $\mathrm{n}^{*}$ \\
\hline Absence of mineral salt & 9.3 \\
\hline$+\mathrm{NaNO}_{3}(4.67 \mathrm{~mol} / \mathrm{l})$ & 12.6 \\
\hline$+\mathrm{Na}_{2} \mathrm{CO}_{3}(3.76 \mathrm{~mol} / \mathrm{l})$ & 13.5 \\
\hline$+\mathrm{Na}_{2} \mathrm{SO}_{4}(2.36 \mathrm{~mol} / \mathrm{l})$ & 14.6 \\
\hline$+\mathrm{Na}_{2} \mathrm{SO}_{4}(1.79 \mathrm{~mol} / \mathrm{l})$ & 15.42 \\
\hline$+\mathrm{KCl}(5.5 \mathrm{~mol} / \mathrm{l})$ & 7.19 \\
\hline$+\mathrm{KBr}(3.53 \mathrm{~mol} / \mathrm{l})$ & 6.98 \\
\hline$+\mathrm{KJ}(1.04 \mathrm{~mol} / \mathrm{l})$ & 10.6 \\
\hline$+\mathrm{K}_{2} \mathrm{SO}_{4}(0.47 \mathrm{~mol} / \mathrm{l})$ & 14.35 \\
\hline
\end{tabular}




\section{Conclusions}

The binodal curves for PEG 6000 + sodium citrate + water system at $298.15 \mathrm{~K}$ were constructed and adequately fitted with a non-linear equation. The leastsquares method was used to define the tendency angle of the tie line. With the influence of salts (sodium sulfate, sodium carbonate, sodium nitrate, potassium sulfate, potassium chloride, potassium iodide, potassium bromide), the obtained binodal curve was slipped to the beginning of coordinate at the low concentrations. Two-phase systems occurred with a low concentration of components (PEG and salt) at a low concentration of polymer and salt, which formed phases. To quantitatively characterize the difference in the affinity of the phases to the distributing substance, we studied the separating ability $\left(n^{\star}\right)$ of the biphasic PEG (6000)-sodium citrate-water system at $\mathrm{T}=298.15 \mathrm{~K}$ in the absence and presence of various additives. With the addition of sodium sulfate $\left(n^{*}=14.6\right.$ in the presence of $2.36 \mathrm{~mol} / \mathrm{l}$ of sodium sulfate, while $\mathrm{n}^{\star}=9.3$ in the absence of additives), the structuring of the aqueous environment took place, which led to a decrease in PEG hydration and deterioration in hydrophobic phases. An increase in the distribution coefficient increases the separation capacity of the system. The effect of salts on the binodal curve and significant increase in the separating ability of the investigated biphasic system indicates that these salts (sodium sulfate, sodium carbonate, sodium nitrate, potassium sulfate, potassium chloride, potassium iodide, potassium bromide) very strongly stabilize the structures of the aqueous medium in the phases of the aqueous biphasic system.

The studied systems can create conditions that enable the separation and extraction of various biological objects, which promises potential application in biotechnology and pharmacology.

\section{Conflicts of Interest}

There are no conflicts to declare.

\section{References}

[1] Albertson, P. (1970) Partition of Cell Particles and Macromolecules in Polymer TwoPhase Systems. Advances in Protein Chemistry, 24, 309-341.

[2] Masimov, E., Bagirov, T., Mahmudov, A., Zaslavski, B. (2018) Phase Separation in Liquid Solutions. Journal of Baku Engineering University, 21, 77-88.

[3] Masimov, E.A., Hasanov, A.A. and Hasanova, H.T. (2015) "Structural Temperature" and Free Energy of Activation of Viscous Flow of Aqueous Solutions. International Journal of Applied and Fundamental Research, 4, 40-44.

[4] Masimov, E.A., Ismailov, E.H. and Odzhaqverdiyeva, S.Y. (2015) Complexation of Polyethylene-Glycol with the Sodium Salts of Citric and Succinic Acids in the Aqueous Solutions. Studies by Dynamic Light Scattering and UV/VIS Spectrophotometry. Journal of Advances in Chemistry, 11, 3866-3872 https://doi.org/10.24297/jac.v11i8.2192

[5] Zaslavsky, B.Y., Bagirov, T.O., Borovskaya, A.A., et al. (1989). Structure of Water as a Key Factor of Phase Separation in Aqueous Mixtures of Two Nonionic Polymers. Polymer, 30, 2104-2111. https://doi.org/10.1016/0032-3861(89)90301-7 
[6] Albertson, P.-A. (1958) Particle Fractionation in Liquid Two-Phase Systems the Composition of Some Phase Systems and the Behaviour of Some Model Particles in Them Application to the Isolation of Cell Walls From Microorganisms. Biochimica et Biophysica Acta, 27, 378-394. https://doi.org/10.1016/0006-3002(58)90345-7

[7] Zaslavsky, B.Y. and Masimov, E.A. (1988) Methods of Analysis of the Relative Hydrophobicity of Biological Solutes. In: Physical Organic Chemistry, Vol. 146, Springer, Berlin, Heidelberg, 171-202. https://doi.org/10.1007/BFb0111257

[8] Raja, S. and Murty, V.R. (2013) Optimization of Aqueous Two-Phase Systems for the Recovery of Soluble Proteins from Tannery Wastewater Using Response Surface Methodology. Journal of Engineering, 2013, Article ID: 217483. https://doi.org/10.1155/2013/217483

[9] Mazzola, P.G., Lopes, A.M., Hasmann, F.A., Jozala, A.F., Penna, T.C., Magalhaes, P.O., Rangel-Yagui, C.O., Pessoa Jr., A. (2008) Liquid-Liquid Extraction of Biomolecules: An Overview and Update of the Main Techniques. Journal of Chemical Technology \& Biotechnology, 83, 143-157. https://doi.org/10.1002/jctb.1794

[10] Chaiko, D.J., Zaslavsky, B., Rollins, A.N., Vojta, Y., Gartelmann, J. and Mego, W. (1996) Metal Separations Using Aqueous Biphasic Partitioning Systems. Office of Scientific and Technical Information, United States. https://doi.org/10.2172/231396

[11] Iqbal, M., Tao, Y., Xie, S., Zhu, Y., Chen, D., Wang, X., et al. (2016) Aqueous TwoPhase System (ATPS): An Overview and Advances in Its Applications. Biological Procedures Online, 18, Article No. 18. https://doi.org/10.1186/s12575-016-0048-8

[12] Da Silva, L.H.M. and Loh, W. (2006) Aqueous Two-Phase Systems: Fundamentals and Applications for Partitioning/Purification of Proteins. Química Nova, 29, 13451351. https://doi.org/10.1590/S0100-40422006000600033

[13] Zafarani-Moattar, M.T., Hamzehzadeh, S. and Nasiri, S. (2012) A New Aqueous Biphasic System Containing Polypropylene Glycol and a Water-Miscible Ionic Liquid. Biotechnology Progress, 28, 146-156. https://doi.org/10.1002/btpr.718

[14] Barani, A., Pirdashti, M., Heidari, Z. and Dragoi, E.-N. (2018) Influence of the Molecular Weight of Polymer, Temperature and $\mathrm{pH}$ on Phase Diagrams of Poly (Ethylene Glycol) + di-potassium Tartrate Aqueous Two-Phase Systems. Fluid Phase Equilibria, 459, 1-9. https://doi.org/10.1016/j.fluid.2017.11.037

[15] Barbosa, A.A., Bonomo, R.C.F., Martins, C.V., Fontan, R.C.I., Júnior, E.C.S., Minim, L.A. and Pignata, M.C. (2016) Equilibrium Data and Physical Properties of Aqueous Two-Phase Systems Formed by PEG (1500 and 4000) g. $\mathrm{mol}^{-1}+$ Sodium Sulfate + Water at Different Temperatures and $\mathrm{pH}$ 2. Journal of Chemical \& Engineering Data, 61, 3-11. https://doi.org/10.1021/je5008586

[16] Han, J., Wang, Y., Yu, C., Li, Y., Kang, W. and Yan, Y. (2012) (Liquid + liquid) Equilibrium of (Imidazolium ioNic Liquids + Organic Salts) Aqueous Two-Phase Systems at $\mathrm{T}=298.15 \mathrm{~K}$ and the Influence of Salts and Ionic Liquids on the Phase Separation. The Journal of Chemical Thermodynamics, 45, 59-67. https://doi.org/10.1016/j.jct.2011.09.004

[17] Liu, Y., Wu, Z. and Zhao, Y (2015) Liquid-Liquid Equilibrium Correlation of Aqueous Two-Phase Systems Composed of Polyethylene Glycol and Nonionic Surfactant. Thermochimica Acta, 602, 78-86. https://doi.org/10.1016/j.tca.2015.01.013

[18] Raja, S. and Murty, V.R. (2013) Liquid-Liquid Equilibrium of Poly (Ethylene Glycol) $6000+$ Sodium Succinate + Water System at Different Temperatures. The Scientific World Journal, 2013, Article ID: 819259.

https://doi.org/10.1155/2013/819259 
[19] Ferreira, L.A. and Teixeira, J.A. (2011) Salt Effect on the Aqueous Two-Phase System PEG 8000-Sodium Sulfate. Journal of Chemical \& Engineering Data, 56, 133137. https://doi.org/10.1021/je1010467

[20] Zaslavsky, B.Yu., Bagirov, T.O., Borovskaya, A.A., et al. (1986) Aqueous Biphasic Systems Formed by Nonionic Polymers I. Effects of Inorganic Salts on Phase Separation. Colloid and Polymer Science, 264, 1066-1071.

https://doi.org/10.1007/BF01410324

[21] Zaslavski, B.Y., Mahmudov, A.U., Bagirov, T.O., Borovskaya, A.A. and Rodnikova, M.N. (1987) Aqueous Biphasic Systems Formed by Nonionic Polymers II. Concentration Effects of Inorganic Salts of Phase Separation. Colloid and Polymer Science, 265, 548-552. https://doi.org/10.1007/BF01412510

[22] Zhang, K., Su, T., Cheng, F., Lin, Y., Zhou, M., Zhu, P., Li, R., Wu, D. (2020) Effect of Sodium Citrate/Polyethlene Glycol on Plasticization and Retrogradation of Maize Stratch. International Journal of Biological Macromolecules, 154, 1471-1477. https://doi.org/10.1016/j.ijbiomac.2019.11.028

[23] Samoilov, O.Y. (1967) Structure of Water Solutions of Electrolytes. USSR Art. 1518, 1967 (in Russian). 